\title{
Calmodulin-stimulated Cyclic Nucleotide Phosphodiesterase (PDE1C) Is Induced in Human Arterial Smooth Muscle Cells of the Synthetic, Proliferative Phenotype
}

\author{
Sergei D. Rybalkin, ${ }^{\star}$ Karin E. Bornfeldt, ${ }^{\ddagger}$ William K. Sonnenburg, ${ }^{\star}$ Irina G. Rybalkina, ${ }^{\star}$ Keith S. Kwak, ${ }^{\star}$ Kim Hanson, ${ }^{\S}$ \\ Edwin G. Krebs, ${ }^{\star}$ and Joseph A. Beavo* \\ $*$ Department of Pharmacology, ${ }^{\star}$ Department of Pathology, and ${ }^{\S}$ Department of Anesthesiology, University of Washington, Seattle, \\ Washington 98195
}

\begin{abstract}
The diversity among cyclic nucleotide phosphodiesterases provides multiple mechanisms for regulation of cAMP and cGMP in the cardiovascular system. Here we report that a calmodulin-stimulated phosphodiesterase (PDE1C) is highly expressed in proliferating human arterial smooth muscle cells (SMCs) in primary culture, but not in the quiescent SMCs of intact human aorta. High levels of PDE1C were found in primary cultures of SMCs derived from explants of human newborn and adult aortas, and in SMCs cultured from severe atherosclerotic lesions. PDE1C was the major cAMP hydrolytic activity in these SMCs. PDE expression patterns in primary SMC cultures from monkey and rat aortas were different from those from human cells. In monkey, high expression of PDE1B was found, whereas PDE1C was not detected. In rat SMCs, PDE1A was the only detectable calmodulin-stimulated PDE. These findings suggest that many of the commonly used animal species may not provide good models for studying the roles of PDEs in proliferation of human SMCs. More importantly, the observation that PDE1C is induced only in proliferating SMCs suggests that it may be both an indicator of proliferation and a possible target for treatment of atherosclerosis or restenosis after angioplasty, conditions in which proliferation of arterial SMCs is negatively modulated by cyclic nucleotides. (J. Clin. Invest. 1997. 100:2611-2621.) Key words: atherosclerosis - angioplasty - Western blotting - RNA probes • ion-exchange chromatography
\end{abstract}

\section{Introduction}

Smooth muscle cells (SMCs) ${ }^{1}$ in the normal arterial wall have a quiescent, contractile phenotype and are resistant to mitogenic stimuli. However, injury to the arterial wall results in a pheno-

Some of the data reported here were presented in preliminary form at the Fourth Meeting of the International Union of Biochemistry and Molecular Biology, in Edinburgh, Scotland in 1996, and in abstract form (1996. Biochem. Soc. Trans. 24:582S).

Address correspondence to Dr. J.A. Beavo, Department of Pharmacology, Box 357280, University of Washington, Seattle, WA 98195. Phone: 206-543-4006; FAX: 206-685-3822; E-mail: beavo@ u.washington.edu

Received for publication 28 March 1997 and accepted in revised form 15 September 1997.

J. Clin. Invest.

(C) The American Society for Clinical Investigation, Inc. 0021-9738/97/11/2611/11 \$2.00

Volume 100, Number 10, November 1997, 2611-2621

http://www.jci.org typic change in the SMCs that enables them to respond to growth factors and to proliferate (1). This synthetic phenotype is characterized by loss of contractile elements and increased synthesis of proteins such as growth factors and their receptors. The change of phenotype leading to proliferation of SMCs are a key event in the formation and progression of lesions of atherosclerosis and in restenosis after angioplasty. Isolation and culturing of SMCs are associated with a similar phenotypic change from a contractile to a synthetic, proliferative phenotype (2). The molecular mechanisms of modulation from the quiescent to the proliferative phenotype are not fully understood.

Cyclic nucleotides (cAMP and cGMP) have a well-established role in regulating vascular tone $(3,4)$. Agents that activate adenylyl or guanylyl cyclase cause relaxation of contracted smooth muscle. Targets for cAMP and cGMP action include cAMP-dependent and cGMP-dependent protein kinases, respectively, and interaction of these targets with cyclic nucleotides culminates in vasorelaxation.

In addition to regulating smooth muscle tone, cyclic nucleotides inhibit SMC proliferation (5). Proliferation of SMCs is regulated by several intracellular signaling pathways, and cyclic nucleotides have been found to counteract many of these pathways. For example, it has been shown that cAMP-dependent protein kinase inhibits the mitogen-activated protein kinase cascade $(6-8)$, the p70 S6 kinase $(9,10)$, and the cyclindependent kinase 4 (11) and mediates cell cycle arrest (12). Thus, it has been proposed that cAMP acts as a gate for mitogenic signaling pathways (13). Less is known about the crosstalk of cGMP and mitogenic signaling pathways that mediate SMC proliferation. However, cGMP can inhibit proliferation.

The degradation of cyclic nucleotides is catalyzed by many cyclic nucleotide phosphodiesterases (PDEs). Currently, seven PDE gene families have been described based on their different sequences, kinetic properties, regulatory mechanisms, and sensitivities to pharmacological inhibitors (14). More than 30 PDEs with different functional characteristics and tissue expression arise from multiple genes and/or alternative splicing within these gene families (15). PDE1 (calmodulin [CaM]dependent PDE), PDE2 (cGMP-stimulated PDE), PDE3 (cGMP-inhibited PDE), PDE4 (cAMP-specific PDE), and PDE5 (cGMP-specific PDE), have been identified in the arterial wall of a wide variety of species, including humans (16-19). The expression patterns of the various PDE isoforms have displayed considerable variability between species.

PDE inhibitors cause relaxation of isolated arterial smooth muscle, and, in general, the extent of the relaxation correlates

1. Abbreviations used in this paper: CaM, calmodulin; GST, glutathione-S-transferase; HRP, horseradish peroxidase; PDE, phosphodiesterase; RT, reverse transcription; SMC, smooth muscle cell. 
with the particular PDE isoform that was inhibited (17, 20-22). For example, PDE3 inhibitors alone or in combination with selective inhibitors of PDE4 have been shown to be potent in relaxing aortic smooth muscle, whereas PDE4-selective inhibitors alone are less effective. These results suggest that PDE3 is the most important isozyme for catalyzing the hydrolysis of the cAMP pool involved in regulating arterial smooth muscle tone, at least in rats.

Although relatively fewer studies have been reported, treatment of arterial SMCs with PDE inhibitors has also been shown to inhibit proliferation. In contrast to the well-documented effects of PDE type-selective inhibitors on arterial smooth muscle tone, PDE3 or PDE4 inhibitors alone did not attenuate effectively proliferation of SMCs derived from pig aorta or rat embryonic aorta $(23,24)$. However, PDE3- and PDE4-selective inhibitors in combination were effective for inhibiting proliferation. A likely explanation for this result might be that both PDE3 and PDE4 are important for regulating cAMP metabolism associated with progression through the cell cycle in pig and rat SMCs. Moreover, these reports suggest that the effect of cAMP formed in these cells may be attenuated positively by inhibiting cAMP degradation.

Previous studies examining the PDE expression profile of aortic tissue and SMCs have relied on anion-exchange chromatographic or drug sensitivity methodologies that by themselves are inadequate for resolving the many different PDE isozymes that have been identified using recombinant DNA techniques. Also, no data have been reported describing the PDE expression pattern in primary cultures of human arterial SMCs, which display a synthetic, proliferative phenotype. The main goal of this study was to identify the PDE isoforms expressed in human proliferating SMCs in primary culture and in aortic smooth muscle from intact human aorta in which the SMCs are quiescent. We also present data examining the PDE expression profile from aorta and SMCs from other experimentally useful species such as monkey and rat. Using molecular probes, such as isozyme-specific antibodies and antisense riboprobes, which can distinguish PDE isoforms based on structural criteria, we show here that a CaM-dependent PDE, PDE1C, is highly expressed in human SMCs of the proliferative phenotype but not in primary cultures of monkey or rat SMCs. This PDE1C isoform is the main cAMP hydrolytic activity in human proliferating SMCs in the presence of calcium. Expression of PDE1C may be an important component in signal transduction pathways mediated by calcium that permit cell cycle traverse and proliferation. The variability of PDE expression among different species presented here points to a need to evaluate the therapeutic utility of PDE inhibitors as well as other drugs using in vitro systems that more closely mirror human cells.

\section{Methods}

Reagents. Pepstatin and leupeptin were obtained from BoehringerMannheim Biochemicals (Indianapolis, IN). The Mono Q anionexchange column (HR 5/5), pGEX-3X vector, and pGEX-4T-1 vector were supplied by Pharmacia Biotech (Piscataway, NJ). The MicroFastTrack ${ }^{\circledR}$ mRNA isolation kit, pCRII vector, pVL1393 vector, and Sf9 cells were from Invitrogen Corp. (Carlsbad, CA). The Maxiscript ${ }^{\circledR}$ in vitro transcription kit and RPA $\mathrm{II}^{\circledR}$ ribonuclease protection assay kit were obtained from Ambion, Inc. (Austin, TX). SulfoLink ${ }^{\circledR}$ kit, AminoLink ${ }^{\circledR}$ kit, $m$-maleimidobenzoyl- $N$-hydroxysuccinimide es- ter, and SuperSignal ${ }^{\circledR}$ chemiluminescent substrate were from Pierce Chemical Co. (Rockford, IL). BacPAK6 DNA (Bsu36 I digest) was from CLONTECH Laboratories, Inc. (Palo Alto, CA). Horseradish peroxidase (HRP)-conjugated goat anti-rabbit IgG and molecular weight protein standards were from Bio-Rad Laboratories (Hercules, CA). $\left[{ }^{3} \mathrm{H}\right] \mathrm{cAMP},\left[{ }^{3} \mathrm{H}\right] \mathrm{cGMP}$, and $\left[{ }^{32} \mathrm{P}\right] \mathrm{UTP}$ were purchased from NEN Research Products (Boston, MA). Taq DNA polymerase and dye terminator cycle sequencing ready reaction DNA sequencing kit were from Perkin-Elmer Corp. (Foster City, CA). The 1-kb DNA ladder, FBS, and DME were obtained from GIBCO BRL (Gaithersburg, MD). Pansorbin ${ }^{\circledR}$ cells were purchased from Calbiochem Corp. (La Jolla, CA). All other reagents were purchased from Sigma Chemical Co. (St. Louis, MO).

Arterial SMC culture and extract preparation. Human newborn arterial SMCs were obtained from the thoracic aortas of infants (2-3 mo) after accidental death, death from Sudden Infant Death Syndrome, or death from congenital defects. Arterial SMCs from adult normal thoracic aortas were obtained from normal donor heart transplants. Arterial SMCs from advanced atherosclerotic lesions were isolated from SMC-rich areas of well-characterized lesions of human adult arteries. Monkey (Macaca nemestrina) SMCs were isolated from the thoracic aorta of adult monkeys obtained from the Regional Primate Center (University of Washington, Seattle, WA). Rat SMCs were isolated from the thoracic aorta of adult $(350-\mathrm{g})$ Sprague-Dawley rats.

Aortas were opened longitudinally, and the endothelial cells were scraped off using a spatula. The smooth muscle layer was then stripped from adventitia and minced in ice-cold PBS. The smooth muscle (for human, 0.5-1 g; for monkey, 5-10 g) was either homogenized immediately or used for establishing cell cultures. The cells were isolated by the explant method and cultured as described previously (25). Cells were used at passages 5-10 and characterized as smooth muscle by morphologic criteria and by expression of smooth muscle $\alpha$-actin. The cells were cultured in DME supplemented with $10 \%$ FBS. Before the experiments, the cells were plated in $100-\mathrm{mm}$ dishes and, when confluent, were incubated in DME $/ \%$ human plasma-derived serum for $2 \mathrm{~d}$. These cells were negative in mycoplasma assays and had a normal chromosome number. Typically, 5-6 plates $\left(3 \times 10^{6}\right.$ cells/plate $)$ were washed three times with cold PBS and harvested in homogenization buffer $(50 \mathrm{mM} \beta$-glycerophosphate, pH 7.3, $1.5 \mathrm{mM}$ EGTA, $0.1 \mathrm{mM} \mathrm{Na}_{3} \mathrm{VO}_{4}, 1 \mathrm{mM}$ DTT, $10 \mu \mathrm{g} / \mathrm{ml}$ aprotinin, $5 \mu \mathrm{g} / \mathrm{ml}$ pepstatin, $20 \mu \mathrm{g} / \mathrm{ml}$ leupeptin, $1 \mathrm{mM}$ benzamidine). Homogenization was carried out using a Polytron homogenizer (Brinkmann Instruments, Inc., Westbury, NY), followed by two sonications for $10 \mathrm{~s}$ using a sonicator (Braun-Sonic 2000; B. Braun Biotech Inc., Allentown, PA) at $50 \%$ output.

Cells from 6 plates were homogenized in $3 \mathrm{ml}$ of homogenization buffer, and aortic tissues were homogenized in $10 \mathrm{vol}$ of the same buffer. The cell extracts were centrifuged at $100,000 \mathrm{~g}$ for $20 \mathrm{~min}$ at $4^{\circ} \mathrm{C}$. The supernatant and pellet were assayed for PDE activity, and the supernatants were used for anion-exchange chromatography.

High performance anion-exchange chromatography. Each supernatant prepared from $\sim 15-20 \times 10^{6}$ cells was loaded at $0.5 \mathrm{ml} / \mathrm{min}$ on a Mono Q anion-exchange column HR 5/5, which had been equilibrated previously with buffer A $(50 \mathrm{mM}$ Tris- $\mathrm{HCl}, \mathrm{pH} 7.5,2 \mathrm{mM}$ EDTA, $1 \mathrm{mM}$ DTT, $1 \mathrm{mM}$ benzamidine). Under this condition, $>95 \%$ of the total PDE activity was bound to the column. The column was washed for $15 \mathrm{~min}$ or until the protein in the eluate (monitored at 280 $\mathrm{nm}$ ) was no longer detected. The bound PDE activity was eluted at a flow of $0.5 \mathrm{ml} / \mathrm{min}$ with a linear gradient $(0-100 \%$ B) of buffer B (buffer $\mathrm{A}+0.8 \mathrm{M} \mathrm{NaCl}$ ) over $40 \mathrm{~min}$. Fractions of $0.25 \mathrm{ml}$ were collected at $4^{\circ} \mathrm{C}$ and assayed for PDE activity. Aliquots of each fraction were boiled in sample buffer for Western blot analysis.

$P D E$ assays, immunoprecipitations, and protein determinations. PDE assays were carried out according to established procedures (26). All assays were performed at $30^{\circ} \mathrm{C}$ using either $1 \mu \mathrm{M}$ cAMP or $1 \mu \mathrm{M}$ cGMP as a substrate in the presence of either $1 \mathrm{mM}$ EGTA or $0.8 \mathrm{mM} \mathrm{CaCl}_{2}$ and $4 \mu \mathrm{g} / \mathrm{ml} \mathrm{CaM}$. 
Immunoprecipitations were performed as described previously using ACC-1 mouse monoclonal IgG, which is reactive with PDE1 enzymes (27). Typically, $200 \mu \mathrm{l}$ of extract was incubated with $200 \mu \mathrm{l}$ of a $10 \%$ suspension of ACC-1 IgG conjugated to Pansorbin ${ }^{\circledR}$ cells supplemented with $1 \mathrm{mM} \mathrm{CaCl}{ }_{2}$ and $0.1 \mu \mathrm{g} / \mathrm{ml} \mathrm{CaM}$, and incubated for $2 \mathrm{~h}$ at $4^{\circ} \mathrm{C}$. The Pansorbin ${ }^{\circledR}$ cells were washed three times by sequentially collecting by centrifugation and resuspending in $400 \mu \mathrm{l}$ of Tris- $\mathrm{HCl}, \mathrm{pH} 7.4,1 \mathrm{mM} \mathrm{CaCl}_{2}$. After the final wash, the cell pellets were resuspended in $400 \mu \mathrm{l}$ of Tris- $\mathrm{HCl}, \mathrm{pH} 7.4$, and assayed subsequently for PDE activity. Protein concentrations were determined by the Bradford method (28).

Preparation of PDE riboprobes and RNase protection assays. Complementary DNA templates for riboprobe synthesis were prepared by a reverse transcription (RT) PCR methodology (29). In brief, human newborn smooth muscle poly(A) mRNA was extracted from tissue using a Micro-FastTrack ${ }^{\circledR}$ kit. The mRNA was reversetranscribed to generate first-strand cDNA as described previously (30). Oligonucleotide sequences corresponding to nucleotides 974994 (sense orientation, 5'-CATCCATGACTACGAGCATAC-3') and 1438-1458 (antisense orientation, 5'-CTTGTGACTGAGCAACCATAG-3') of the cDNA designated HSPDE1C1 (GenBank accession number U40371), and nucleotides 861-881 (sense orientation, 5'-GATCGCTCTGTCCTTGAGAAT-3') and 1302-1322 (antisense orientation, 5'-CTCTGTTGAGTCTGTCAGAAG-3') of the cDNA designated HSPDE1A3 (GenBank accession number U40370) were synthesized using a DNA synthesizer (model 381A; Applied Biosystems, Inc., Foster City, CA). The first-strand cDNA was subjected to 25 cycles of PCR amplification by thermal cycling the reaction mixture (composition: $10 \mathrm{mM}$ Tris- $\mathrm{HCl}, \mathrm{pH} 8.8$, at $25^{\circ} \mathrm{C}, 50 \mathrm{mM} \mathrm{KCl}, 1.5$ $\mathrm{mM} \mathrm{MgCl} 2,0.2 \mathrm{mM}$ [each] dATP, dGTP, dCTP, and dTTP, $0.1 \%$ Triton X-100, 0.2-0.4 ng/ $\mu$ l first-strand cDNA, $1 \mu \mathrm{M}$ sense primer, $1 \mu \mathrm{M}$ antisense primer, and $0.1 \mathrm{U} / \mu \mathrm{l} \mathrm{Taq}$ DNA polymerase) at $94^{\circ} \mathrm{C}$ for $1 \mathrm{~min}$, then $60^{\circ} \mathrm{C}$ for $1 \mathrm{~min}$, followed by $72^{\circ} \mathrm{C}$ for $1 \mathrm{~min}$.

The reaction products were separated on a $1 \%$ low melting point agarose gel containing ethidium bromide, and visualized by illumination with ultraviolet (UV) light. DNA bands of sizes close to those predicted, based on the published sequence and location of the amplification primers, were cut out of the gel using a razor blade and subcloned into the pCRII vector. Putative PDE cDNAs were sequenced using the dye terminator cycle sequencing ready reaction DNA sequencing kit and oligonucleotide primers flanking the multiple cloning site $(31,32)$. The authenticity of the putative human PDE1C and human PDE1A partial cDNAs was determined by comparing the nucleotide sequences with HSPDE1C1 and HSPDE1A3 cDNAs using the Bestfit program in the Genetic Computer Group software package (33). The riboprobe template corresponding to HSPDE1C1 nucleotides 974-1458 was designated $\mathrm{H1C}$, and the riboprobe template corresponding to HSPDE1A3 nucleotides 934-1395 was designated $\mathrm{H} 1 \mathrm{~A}$.

Templates for radiolabeled antisense riboprobe synthesis were prepared by digesting the plasmid DNA with either StyI (H1C), or AvalI (H1A), yielding templates with a riboprobe length of 289 (HSPDE1C1 nucleotides 1169-1458) and 171 (HSPDE1A3 nucleotides 1224-1395) nucleotides, respectively. Radiolabeled antisense riboprobes were transcribed in vitro using the maxiscript kit according to the manufacturer's protocol. The transcription reaction had the following composition: $1 \times$ transcription buffer, $10 \mathrm{mM}$ DTT, $0.5 \mathrm{mM}$ ATP, $0.5 \mathrm{mM}$ GTP, $0.5 \mathrm{mM}$ CTP, $0.05 \mathrm{mM} \mathrm{UTP}, 2.5 \mu \mathrm{Ci} / \mu \mathrm{l}\left[{ }^{32} \mathrm{P}\right] \mathrm{UTP}$ (3,000 Ci $/ \mathrm{mmol}), 0.05 \mu \mathrm{g} / \mu \mathrm{l}$ template DNA, $1.25 \mathrm{U} / \mu \mathrm{l} \mathrm{RNase}$ inhibitor, and $0.5 \mathrm{U} / \mu 1 \mathrm{SP} 6(\mathrm{H} 1 \mathrm{C})$ or T7 (H1A) RNA polymerase.

RNase protection assays were performed using the RNase II kit, following the manufacturer's protocol. The hybridization reaction contained $20 \mu \mathrm{g}$ of total RNA and $100,000 \mathrm{cpm}$ of riboprobe in a 50$\mu l$ reaction. After digestion with RNases, the protected riboprobes were precipitated, reconstituted in $8 \mu$ l of loading buffer, and electrophoresed on a $5 \%$ acrylamide $/ 8 \mathrm{M}$ urea gel containing $1 \times$ Tris/boric acid/EDTA buffer. After electrophoresis, the gel was dried and exposed to $\mathrm{x}$-ray film for $16-24 \mathrm{~h}$ at $-70^{\circ} \mathrm{C}$.
Fusion protein production and peptide synthesis. Glutathione$S$-transferase (GST) fusion proteins were used as immunogens and/or for purification of isoform-selective PDE1 antibodies. A plasmid encoding a PDE1A-GST fusion protein was prepared by subcloning the $\sim 250$ bp XmnI restriction endonuclease cleavage fragment of the MMPDE1A2 cDNA (GenBank accession number U56649) encompassing the carboxy-terminal coding sequence (amino acid residues 500-546) into the pGEX-3X plasmid in-frame with the GST coding sequence.

A plasmid encoding a GST fusion protein containing MMPDE1B1 (GenBank accession number L01695) amino acid residues 446-535 was constructed using a cDNA encompassing MMPDE1B1 nucleotides 79-1772, generated by RT-PCR amplification of mouse brain mRNA. The resulting cDNA was cleaved with StyI restriction endonuclease, recessed ends were filled in with Klenow fragment, and the $\sim 400$-bp fragment was subcloned into the pGEX-3X plasmid inframe with the GST coding sequence (29).

A PDE1C-GST fusion protein plasmid was constructed from the carboxy-terminal coding sequence (amino acid residues 495-768) of the cDNA clone RNPDE1C2 (GenBank accession number L41045) and the pGEX-4T-1 vector (34).

Expression and purification of the fusion proteins were performed from XL1-Blue cells using established procedures (29).

A peptide corresponding to BTPDE5A1 (GenBank accession number L16545) amino acid residues 836-852 (sequence $=\mathrm{NH}_{2}$ CRKNRQKWQALAEQQEK- $\mathrm{CO}_{2} \mathrm{H}$ ) was synthesized using a peptide synthesizer (model 430A; Applied Biosystems, Inc.)

Antisera production. An immunogen for generating rabbit antibodies reactive with PDE5 isozymes was prepared by conjugating the synthetic peptide (see above) to hemocyanin using $m$-maleimidobenzoyl- $N$-hydroxysuccinimide ester (35). Recombinant, baculovirusexpressed BTPDE1A2 was used as an immunogen for generating antibodies reactive with PDE1A (31). PDE1B fusion protein described above was used as immunogen for generating PDE1B-specific antisera. All antisera were produced in rabbits using established protocols (35). Production of PDE1C antisera was reported previously (34).

IgG purification. PDE5 synthetic peptide and PDE1A-, PDE1B-, and PDE1C-GST fusion proteins (see above) were coupled to SulfoLink (PDE5 peptide) or AminoLink (for fusion proteins) gels using the manufacturer's protocol. The PDE-reactive IgGs were purified by affinity chromatography using established procedures (35).

Production of recombinant PDE1 protein. Recombinant baculovirus encoding MMPDE1A2, MMPDE1B1, MMPDE1C1 (GenBank accession number L76944) and MMPDE1C4 (GenBank accession number L76947), were constructed using established methods from the corresponding PDE1 cDNAs (described above and in reference 31), the baculovirus shuttle vector pVL1393, and BacPAK6 viral DNA. Isolated viruses were amplified and used to infect 1-liter cultures of Sf9 cells at a multiplicity of infection of 10 plaque-forming U/cell. After $48 \mathrm{~h}$, the infected cells were harvested, and recombinant PDE1 protein was purified using an ACC-1 immunoaffinity column as described previously (31).

Western blot analysis. Samples were boiled in $1 \times$ sample buffer for $5 \mathrm{~min}$, loaded onto an SDS-polyacrylamide gel (8\% acrylamide/ $0.21 \%$ bisacrylamide), and electrophoresed. The separated proteins were transferred to nitrocellulose and immunostained subsequently with isozyme-specific PDE1 or PDE5 antibodies (29). The immunoreactivity was detected by enhanced chemiluminescence using HRP-conjugated goat anti-rabbit IgGs and HRP-luminescent substrate mixture.

Experimental design. PDE activity and Western blot analyses of anion-exchange chromatography profiles were performed on three human adult aortas, two human newborn aortas, three monkey aortas, and primary SMC cultures from three human adult aortas, four human newborn aortas, two arteries having atherosclerotic lesions and two monkey aortas. At least two HPLC profiles were carried out on each cell strain (i.e., four or more experiments). Three independent RNAse protection assays were performed on total RNA iso- 
lated at two different passages from one of the adult and one of the newborn strains of SMCs in primary culture. The data presented here are representative examples of these experiments.

\section{Results}

Comparison of PDE activity from extracts of human adult aorta and SMCs in primary culture. Cells from normal intact aorta represent SMCs in a quiescent state. More than $90 \%$ of the total cAMP and cGMP hydrolytic activity in these cells was present in the supernatant fraction of human aortic extracts, and addition of $\mathrm{CaM}$ to the assay mixture increased the hydrolysis of cAMP and cGMP by 48 and 97\%, respectively (Fig. 1). The cGMP hydrolytic activity in the soluble fraction was 2.7-fold greater than for cAMP.

To estimate PDE activity in proliferating SMCs and compare that with quiescent cells from intact aorta, we used cells derived from human aortic homogenates in primary culture as a model system. It has been shown previously that human arterial SMCs cultured in vitro undergo phenotypic modulation, becoming proliferative yet maintaining the characteristics of SMCs for up to 10 passages. Most of the cAMP and cGMP PDE activities in the extracts of human adult SMCs in primary culture were found in the cytosolic fraction $(>85 \%)$. In the presence of CaM, both cAMP and cGMP hydrolysis were activated two- to threefold (Fig. 1), which was greater than that observed in extracts from human adult aorta. After immunoprecipitation of the CaM-bound PDE1 from SMC extracts

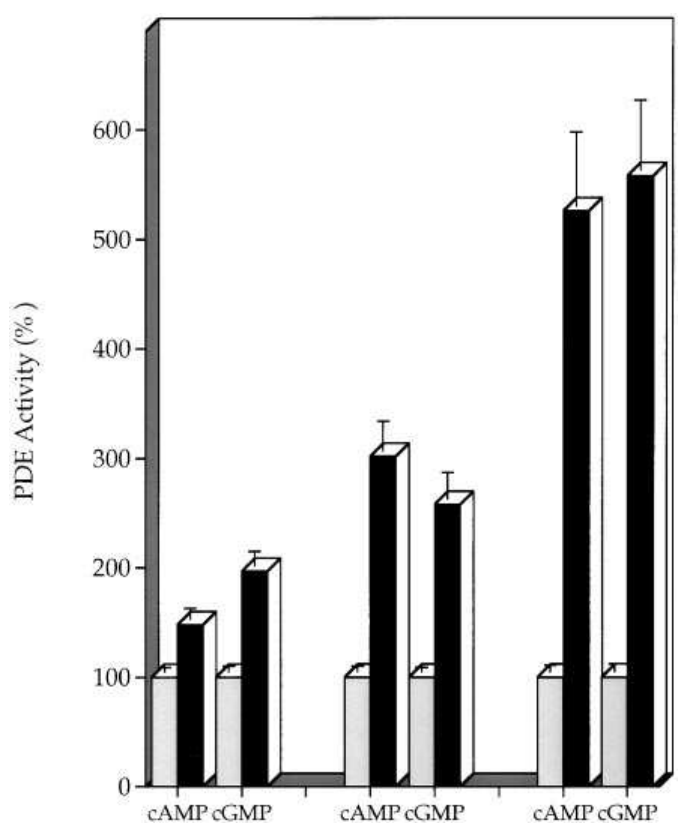

Figure 1. CaM-stimulated PDE is induced in primary culture of human SMCs. Stimulation of PDE activity by $\mathrm{Ca}^{2+}$ and $\mathrm{CaM}$ in extracts of human adult aorta (left), adult SMCs in primary culture (middle), or immunoprecipitates from cultured SMC extracts (right) using the PDE1-reactive antibody, ACC-1. Extract preparation, immunoprecipitation, and assays for PDE activity were carried out as described in Methods. Assays were performed using either $1 \mu \mathrm{M} \mathrm{cAMP}$ or $1 \mu \mathrm{M}$ cGMP in the presence of either $1 \mathrm{mM}$ EGTA (gray bars) or $0.8 \mathrm{mM} \mathrm{CaCl}_{2}$ and $4 \mu \mathrm{g} / \mathrm{ml} \mathrm{CaM}$ (black bars). $100 \%$ activity is defined as the activity of each sample when assayed in the absence of CaM.

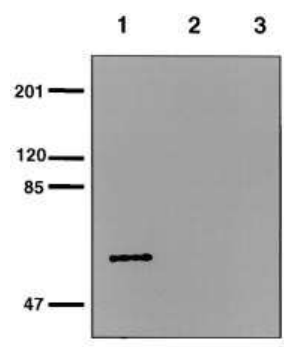

A

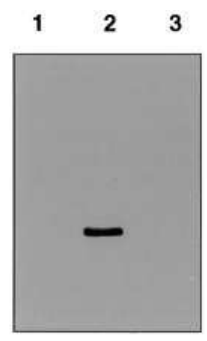

B

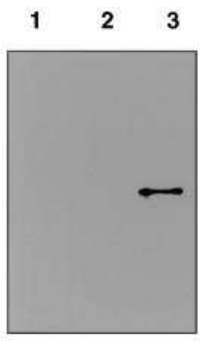

C
Figure 2. Specificity of PDE1A, PDE1B, and PDE1C antibodies was verified by Western blot analysis. 10-20 ng of recombinant PDE1A (lane 1), PDE1B (lane 2), and PDE1C (lane 3) were loaded on SDSpolyacrylamide gels ( $8 \%$ acrylamide) and immunostained with PDE1A $(A)$, PDE1B $(B)$, or PDE1C $(C)$ antibodies. The relative molecular mass $\left(\times 10^{-3}\right)$ of each protein standard is indicated (left).

with the mAb, ACC-1, a five- to sevenfold activation by $\mathrm{CaM}$ was detected (Fig. 1). Kinetic analysis of the immunoprecipitated PDE1s from cultured SMCs indicated the presence of a low $K_{\mathrm{m}}$ cAMP and cGMP PDE1 activity $\left(K_{\mathrm{m}}=2.9 \mu \mathrm{M}\right.$ for cAMP and $2.4 \mu \mathrm{M}$ for cGMP).

Identification of cytosolic PDE isoforms from human adult aortic smooth muscle and human adult SMCs in primary culture. To aid in the identification of which PDE1 isoforms were present in aortic smooth muscle and in SMCs in primary culture, PDE1A-, PDE1B-, and PDE1C-specific antibodies were generated. Each antibody recognized only one isoform, and no cross-reactivity was detected (Fig. 2). Resolution of PDE isoforms expressed in the tissue and cell culture extracts was achieved by anion-exchange chromatography, followed by analysis of the fractions by PDE activity assays and Western blot analysis.

Quiescent cells from human adult aorta displayed several PDE activities resolved by anion-exchange chromatography (Fig. $3 A$ ). Fractions $8-13$ hydrolyzed cGMP with a high degree of selectivity in the presence of EGTA. Western blot analysis with PDE5 antibodies revealed that these fractions contained the PDE5 isozyme. cAMP-hydrolyzing PDEs (PDE3 and PDE4) were eluted later during the gradient (fractions 24-35).

In human adult SMCs in primary culture, the peak of cGMP-hydrolyzing activity (fractions 7-13) also displayed immunoreactivity with PDE5 antibodies (Fig. $3 \mathrm{~B}$ ), and showed retention times similar to PDE5 from adult intact aorta (Fig. $3 A$ ). However, in cultured SMCs, a small peak of cAMP hydrolytic activity was eluted slightly ahead of PDE5 (fractions 7-8), was stimulated 7- to 10-fold by calcium and CaM, and hydrolyzed both cAMP and cGMP with equal efficacy. In contrast, the calcium and CaM-stimulated cyclic nucleotide hydrolytic activity in human aortic smooth muscle catalyzed mainly the hydrolysis of cGMP and eluted later than PDE5 and the PDE1 activity detected in cultured human SMCs.

Using isozyme-specific PDE1 antibodies, the CaM-stimulated peaks of activity detected in human aortic extracts were identified as PDE1A and PDE1B by Western blot analysis (Fig. 3 A). PDE1A was observed as two broad peaks spanning fractions 13-24, with maximal protein detected in fractions 14 and 19. PDE1B immunoreactivity was detected in fractions eluting after PDE1A (fractions 20-23). 


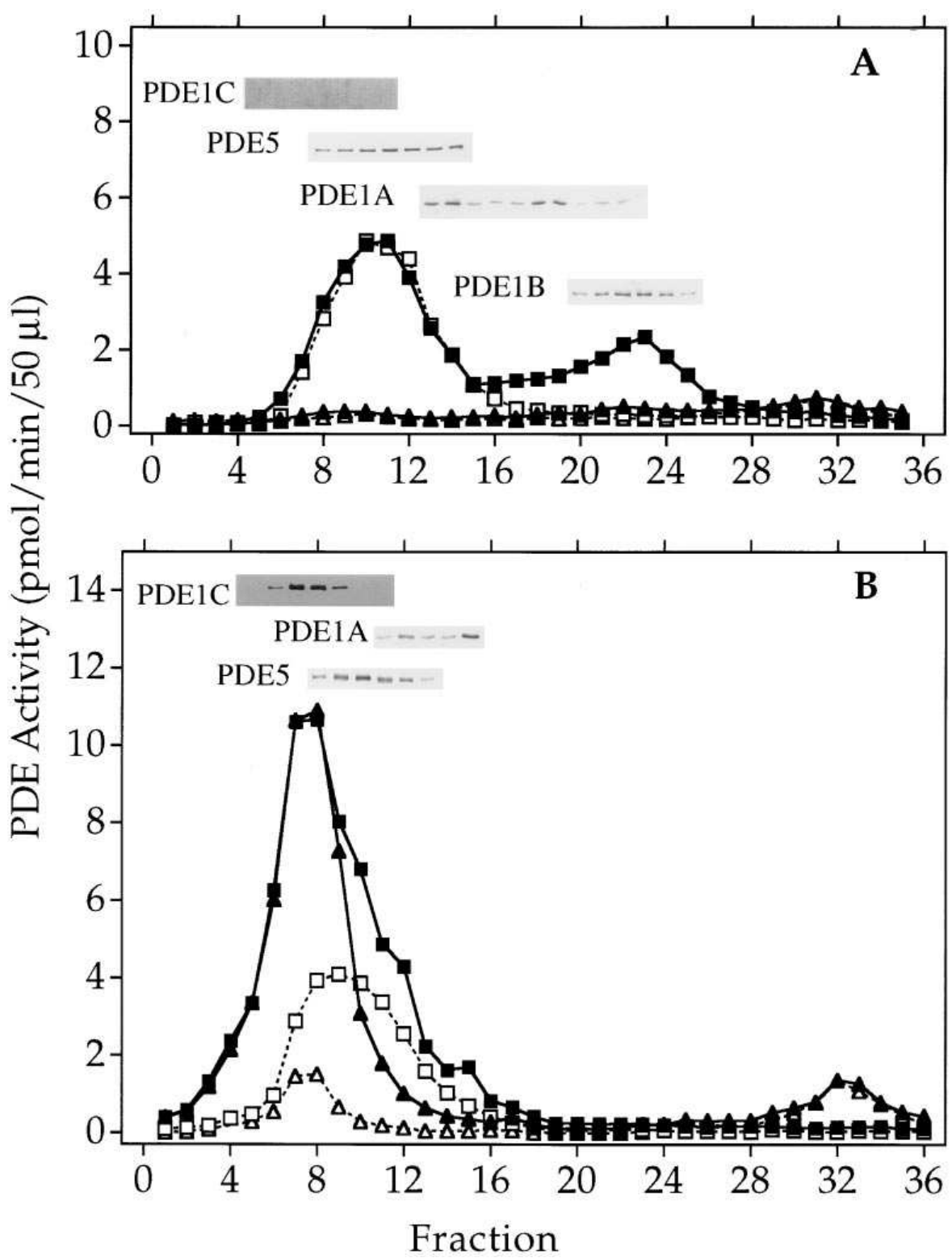

Figure 3. PDE1C is induced in adult SMCs in primary culture. Anion-exchange chromatography of PDE activity from human adult aorta $(A)$ and adult SMCs in primary culture $(B)$. The PDE activity in each fraction was assayed with either $1 \mu \mathrm{M} \mathrm{cAMP}$ (triangles) or $1 \mu \mathrm{M}$ cGMP (squares) in the presence of either $1 \mathrm{mM}$ EGTA (open symbols) or $1 \mathrm{mM} \mathrm{CaCl}_{2}$ and $4 \mu \mathrm{g} / \mathrm{ml} \mathrm{CaM}$ (filled symbols). Isozyme-specific immunoreactivity of each fraction was determined by Western blot analysis as described in Methods. Immunoblots with detectable bands of PDE1A, PDE1B, PDE1C, and PDE5 are shown above their respective chromatographic fractions. PDE1C was not detected in adult aorta $(A)$, as shown by the negative immunoblot in fractions 4-12 using conditions identical to those in $B$.
In human adult SMCs in primary culture, Western blot analysis revealed PDE1C immunoreactivity in the elution fractions containing most of the CaM-stimulated PDE activity (Fig. $3 \mathrm{~B}$ ). In contrast, no PDE1C immunoreactivity was detected in the same fractions from human adult aorta chromatography (Fig. $3 A$ ). In addition to PDE1C, a PDE1A isoform eluting after PDE5 was detected in the fractions of cultured human adult SMCs when probed with PDE1A-specific antibodies. This PDE1A displayed an elution profile with two peaks of activity (fractions 12 and 15). In all but one case, the relative mobility of the PDE1A immunoreactivity detected in adult human aorta and cultured arterial SMCs was nearly identical to that of recombinant BTPDE1A1 $\left(59,000 M_{\mathrm{r}}\right)$. However, in one human aorta, a peak of PDE1A was found that coeluted with the PDE5 peak. The immunoreactivity of that peak appeared to be closer to that of BTPDE1A2 (61 kD; data not shown).

PDE3 and PDE4 isoforms were identified on the basis of the inhibitory potency of their selective inhibitors (enoximone and rolipram, respectively) in fractions 22-36. It was determined that most cAMP hydrolytic activity was due to PDE4 in these fractions (data not shown).

Identification of PDE1 isoforms from human newborn aortic smooth muscle and primary cultures of human newborn SMCs. CaM-PDE activity in human newborn aorta was found to be lower than in human adult aorta. When extracts of human newborn aorta were assayed in the presence of calcium and CaM, cGMP hydrolysis was stimulated by only $18 \%$. Stimulation of cAMP hydrolytic activity by calcium and $\mathrm{CaM}$ in these extracts was not detected. The PDE elution profile obtained from human newborn aorta is shown in Fig. $4 \mathrm{~A}$. A large peak of cGMP hydrolytic activity was detected early during the elution. Only PDE5 was detected in this first peak by Western blot analysis using PDE5 and isoform-specific PDE1 antibodies. A very small peak of CaM-stimulated cGMP hydrolytic activity was detected in fractions 20-25, which corre- 


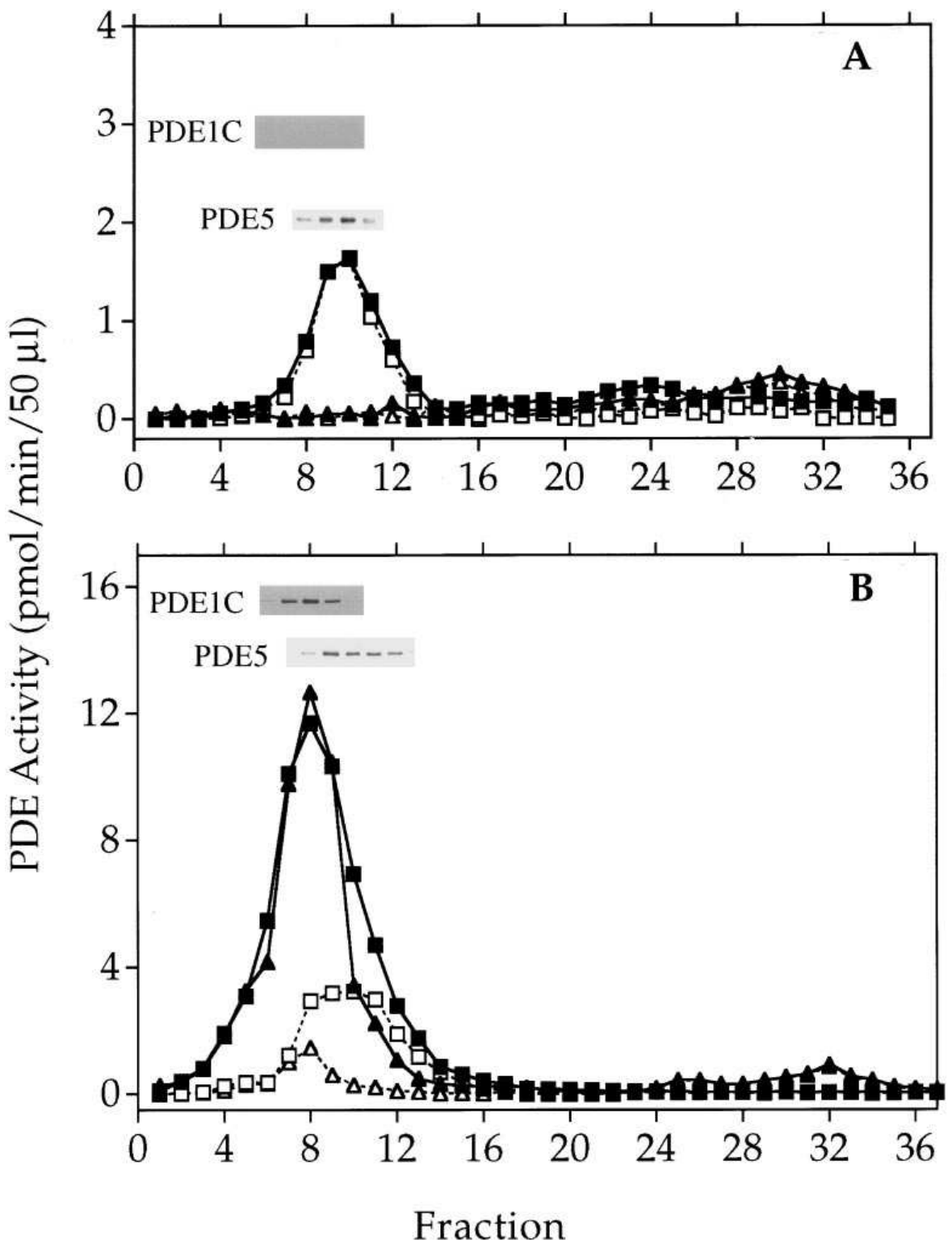

Figure 4. PDE1C is induced in newborn SMCs in primary culture. Anion-exchange chromatography of PDE activity from human newborn aorta $(A)$ and human newborn SMCs in primary culture $(B)$. PDE activity was assayed with either $1 \mu \mathrm{M}$ cAMP (triangles) or $1 \mu \mathrm{M} \mathrm{cGMP}$ (squares) in the presence of either 1 mM EGTA (open symbols) or $1 \mathrm{mM} \mathrm{CaCl}_{2}$ and $4 \mu \mathrm{g} / \mathrm{ml} \mathrm{CaM}$ (filled symbols). Immunoblots with detectable bands of PDE1C and PDE5 are shown above their respective chromatographic fractions. PDE1C was not detected in newborn aorta $(A)$, as shown by the negative immunoblot in fractions $4-12$ using conditions identical to those in $B$. sponds to the retention of PDE1B (see, e.g., Fig. $3 A$ ), but no immunoreactivity could be detected with any of the PDE1 antibodies. Thus, in contrast to adult aorta, PDE1A activity was undetectable, and PDE1B activity was much lower in the newborn aorta.

We were concerned that the age of the aorta might alter the PDE1C expression. However, anion-exchange chromatography of human newborn SMCs in primary culture revealed a PDE elution profile (Fig. $4 B$ ) very similar to that of adult SMCs in primary culture (Fig. $3 \mathrm{~B}$ ). A large peak of calcium and CaM-stimulated cAMP and cGMP hydrolytic activity was detected early in the gradient, followed by a smaller peak of cGMP hydrolytic activity that was insensitive to calcium and CaM. Western blot analysis of these fractions with PDE5 and isoform-specific PDE1 antibodies revealed the presence of PDE1C and PDE5 immunoreactivities. The PDE1C isoforms detected in both human newborn and adult SMCs had identical molecular masses $(\sim 72 \mathrm{kD})$ as estimated by Western blot analysis (Fig. 5). However, unlike adult cultured human arte- rial SMCs, no PDE1A immunoreactivity was detected in newborn cultured human SMCs.

RNase protection assay of PDE1A and PDE1C from human newborn and adult SMCs. To confirm which PDE1 isoforms were expressed in the human SMCs, RT-PCR-generated partial cDNAs corresponding to human PDE1A and PDE1C isoforms were used to probe total RNA extracted from human newborn and adult SMC cultures. The results of RNase protection assays using riboprobes synthesized from these templates are shown in Fig. 6. RNA from both adult and newborn human SMCs completely protected the PDE1C riboprobe (286 bases). However, only the RNA from adult human SMCs completely protected the PDE1A riboprobe (172 bases). These RNase protection data confirm the PDE elution profile from Mono Q anion-exchange chromatography as determined by activity and Western blot analysis, that indicated a high level of PDE1C expression in both newborn and adult SMCs in primary culture, and PDE1A expression only in adult SMCs. 


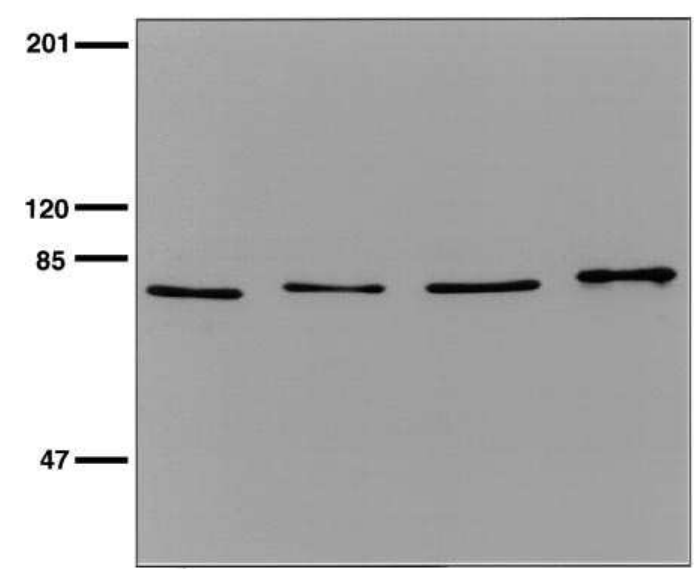

Figure 5. Comparison of molecular masses of PDE1C from human adult and newborn SMCs by Western blot analysis. Recombinant PDE1C1 (lane 1), fraction 8 from anion-exchange chromatography of human adult SMCs (lane 2) and of human newborn SMCs (lane 3), and recombinant PDE1C4 (lane 4) were loaded on an SDS-polyacrylamide gel ( $8 \%$ acrylamide) and Western blotted using PDE1Cspecific antibodies. The relative molecular mass $\left(\times 10^{-3}\right)$ of each protein standard is indicated (left).

Identification of PDE1 isoforms from primary cultures of human aortic SMCs isolated from advanced atherosclerotic lesions. Samples from endarterectomy specimens were obtained from patients with severe, advanced atherosclerotic lesions,

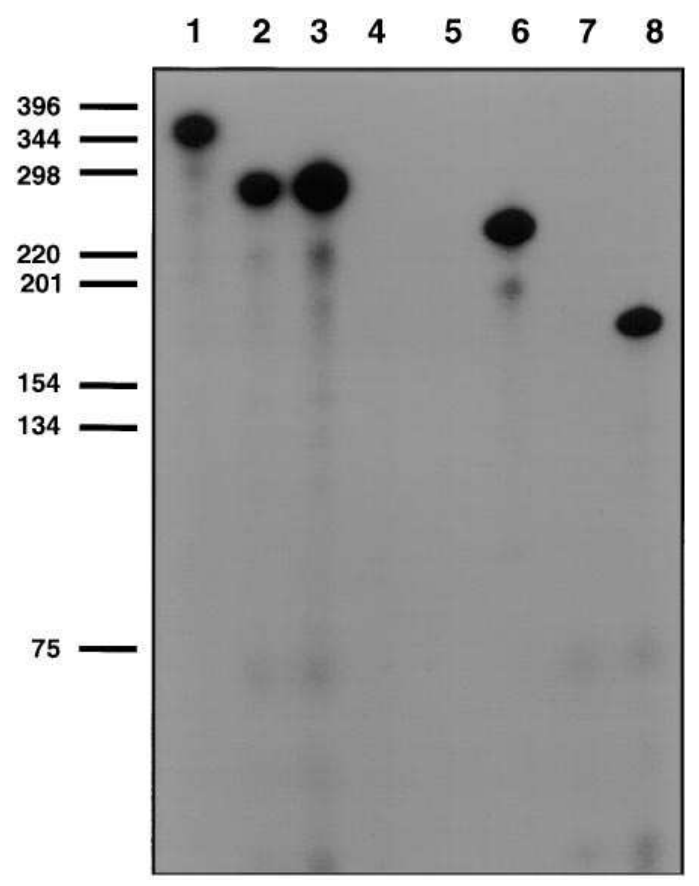

Figure 6. Adult and newborn SMCs express PDE1C mRNA, but only adult SMCs express PDE1A mRNA. RNase protection analysis of human total RNA extracted from adult and newborn SMCs in primary culture using PDE1A (lanes 5-8) and PDE1C (lanes 1-4) riboprobes. Lanes 1 (PDE1C) and 6 (PDE1A) represent probes alone. $20 \mu \mathrm{g}$ of total RNA extracted from human adult (lanes 3 and 8 ) and newborn SMCs (lanes 2 and 7) and $10 \mu \mathrm{g}$ tRNA (lanes 4 and 5) were assayed. The molecular masses (bases) of a DNA ladder are indicated (left).

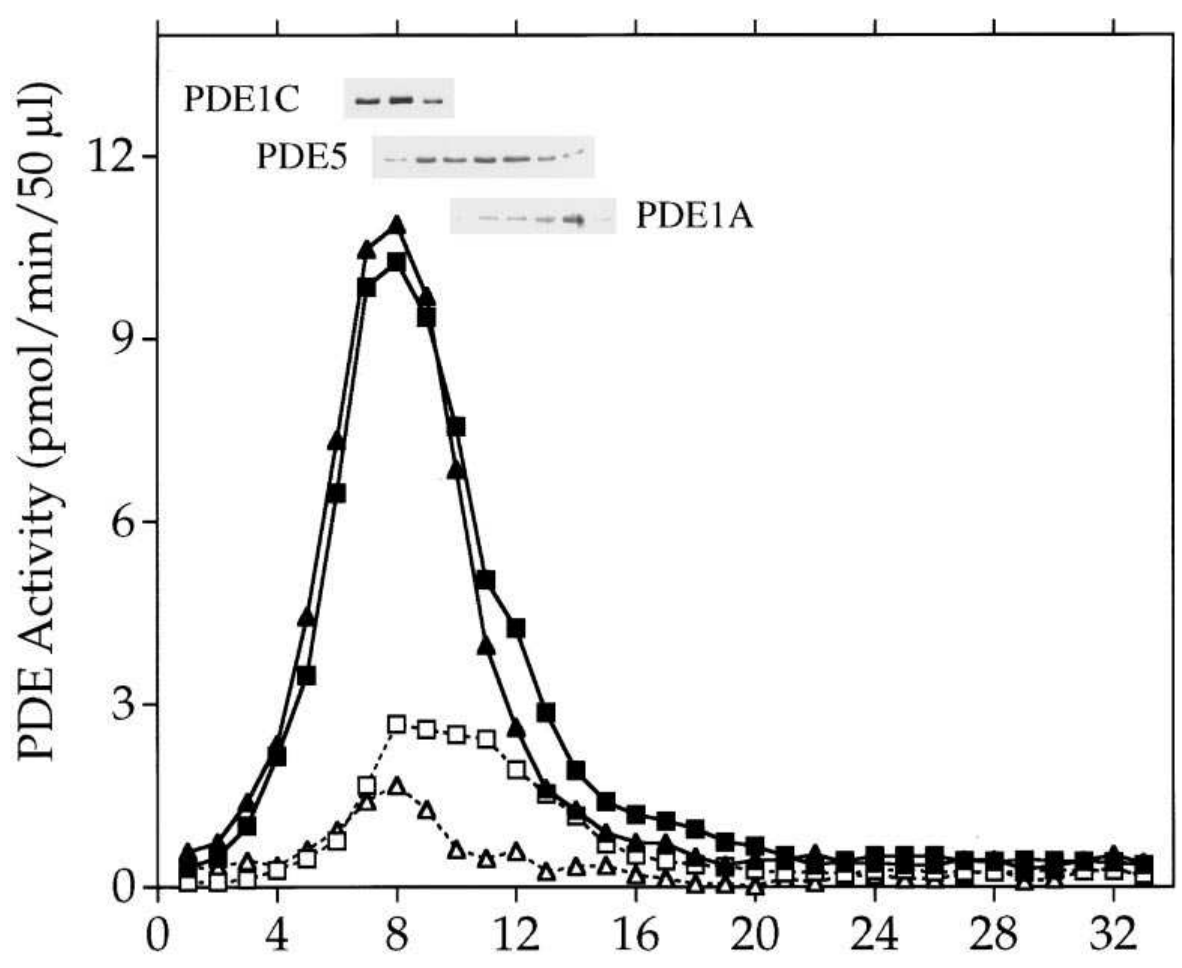

Fraction
Figure 7. PDE1C is expressed in cultured human SMCs from an atherosclerotic lesion. Anion-exchange chromatography of PDE activity from human SMCs derived from explanted smooth muscle of an atherosclerotic lesion from a carotid artery. The tissue was an endarterectomy specimen from a patient who had undergone elective surgery. PDE activity was assayed using either $1 \mu \mathrm{M}$ cAMP (triangles) or $1 \mu \mathrm{M}$ cGMP (squares) in the presence of either $1 \mu \mathrm{M}$ EGTA (open symbols) or $1 \mathrm{mM} \mathrm{CaCl}_{2}$ and $4 \mu \mathrm{g} / \mathrm{ml} \mathrm{CaM}$ (filled symbols). Immunoblots with detectable bands of PDE1A, PDE1C, and PDE5 are shown above their respective chromatographic fractions. 
which contained SMCs mostly in the nonproliferative state. However, after growing in primary culture, the phenotypic state of these cells was changed to proliferative. Separation of PDE activities by anion-exchange chromatography of SMCs isolated from a severe atherosclerotic lesion in a carotid artery and then grown in culture for several passages also displayed a high level of PDE1C expression (Fig. 7), as was found in primary cultures of SMCs from normal aortas (Figs. 3 and 4). PDE1A activity eluted at a similar position as PDE1A activity from human adult aortic SMCs, after the PDE5 activity (Fig. 3 B). PDE1C expression was also seen in SMCs grown from the severe lesion in a thoracic artery of another patient (data not shown). The results are consistent with the idea that PDE1C can be found in proliferating cells in primary culture derived from all types of arterial SMCs, isolated from different vascular beds, different ages, and different disease states.

Characterization of PDEs from monkey aortic smooth muscle and SMC primary cultures. To be able to determine if SMCs proliferating in an intact animal artery also exhibit the same phenotype as those in culture, including expression of PDE1C, a good animal model system is required. Anion-exchange chromatography of PDEs from monkey aorta (Fig. $8 A$ ) or cultured SMCs (Fig. $8 B$ ) displayed similar, but not identical, profiles. Unfortunately, no expression of PDE1C could be detected in the monkey SMCs. For both aortic and SMC culture extracts, a large peak of CaM-independent, cGMP hydrolytic activity having immunoreactivity with PDE5 antibodies eluted first. Also common to both samples was the later elution of a CaM-stimulated, cGMP and cAMP hydrolytic activity (fractions 19-24). These fractions had a greater capacity to hydrolyze cGMP than cAMP and displayed immunoreactivity with PDE1B antibodies. Moreover, Western blot analysis of elution fractions from aorta and cultured SMC extracts showed PDE1B-immunoreactive bands with mobilities slightly greater than recombinant mouse PDE1B (63 kD) (Fig. 9). In monkey aorta extracts, another CaM-stimulated cGMP hydrolytic ac-

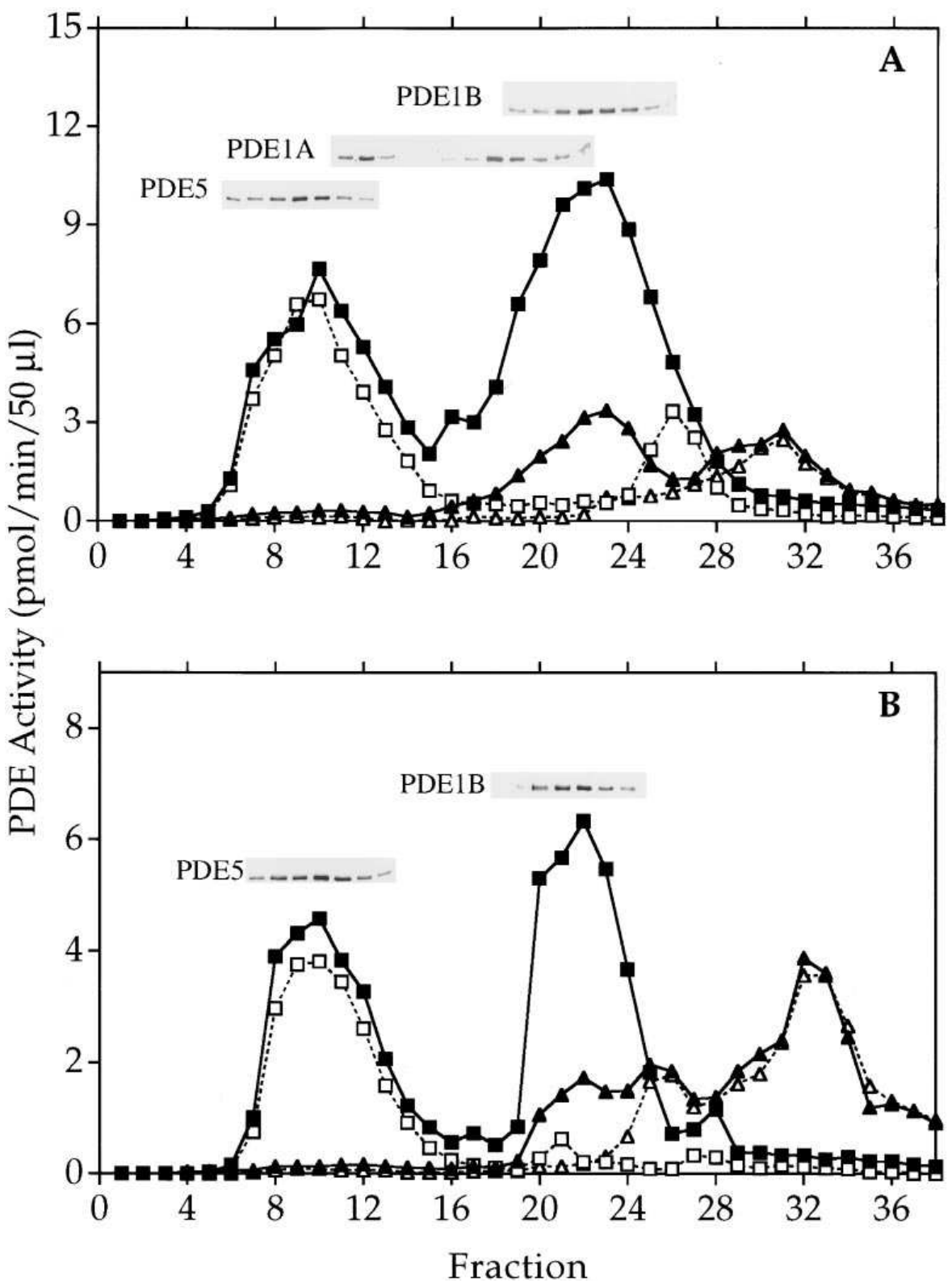

Figure 8. Monkey SMCs do not express PDE1C but do express PDE1A and PDE1B. Anion-exchange chromatography of PDE activity from monkey (M. nemestrina) aorta $(A)$ and monkey SMCs in primary culture $(B)$. PDE activity was assayed with either $1 \mu \mathrm{M}$ cAMP (triangles) or $1 \mu \mathrm{M}$ cGMP (squares) in the presence of either 1 mM EGTA (open symbols) or $1 \mathrm{mM} \mathrm{CaCl}_{2}$ and $4 \mu \mathrm{g} / \mathrm{ml} \mathrm{CaM}$ (filled symbols). Immunoblots with detectable bands of PDE1A, PDE1B, and PDE5 are shown above their respective chromatographic fractions. 


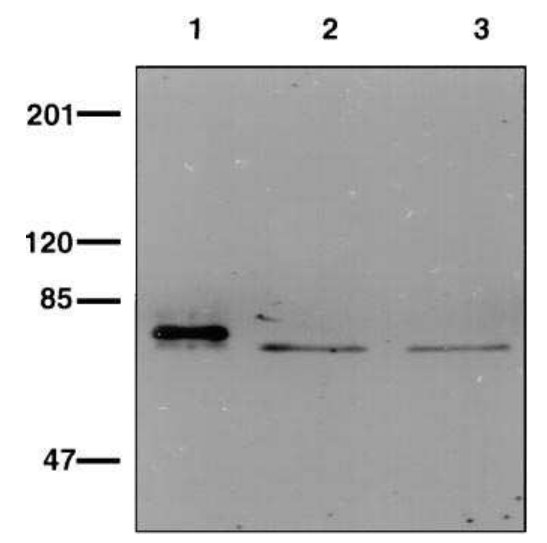

ted with PDE1B-specific antibodies. The relative molecular mass $\left(\times 10^{-3}\right)$ of each protein standard is indicated (left).

tivity was detected later in the first large peak of activity and again early in the second large peak of cGMP and cAMP hydrolytic activity. These fractions displayed little cAMP hydrolytic activity at a concentration of $1 \mu \mathrm{M}$ substrate and had immunoreactivity with PDE1A-specific antibodies. PDE1A activity and immunoreactivity were not detected in extracts of cultured monkey SMCs. In both samples, no immunoreactivity with PDE1C-specific antibodies could be detected in any of the fractions. A PDE activity in fractions 25-27 was stimulated by $1 \mu \mathrm{m}$ cGMP, indicating the presence of small amounts of PDE2 in cultured monkey SMCs and aorta (data not shown).

Identification of PDE1 isoforms from primary cultures of rat SMCs. Another system commonly used to study SMC proliferation is the rat aorta balloon angioplasty model. Anion HPLC of cultured proliferating rat SMCs (Fig. 10) showed a large peak of cGMP hydrolytic activity. This peak contained two activities: early fractions were completely CaM-independent and displayed immunoreactivity with PDE5 antibodies, whereas later fractions displayed slight stimulation by calcium and $\mathrm{CaM}$ and were reactive with PDE1A antibodies. Again, no PDE1C could be detected.

\section{Discussion}

In this study, we have identified a cyclic nucleotide PDE isozyme (PDE1C) that is expressed in proliferating but not in nonproliferating human smooth muscle. Moreover, this isozyme is not expressed in smooth muscle of several other species. In contrast to nearly all previous reports, these studies have made use of molecular probes that allow identification of the specific isoforms present in the muscle tissue; this has allowed identification of a previously unknown complexity of PDE expression.

A major new finding is that human SMCs grown in primary culture express high levels of a PDE1C isozyme, whereas no PDE1C was detected in smooth muscle acutely isolated from the medial layer of human aorta. This enzyme has an equal capacity to hydrolyze both cAMP and cGMP, with a $K_{\mathrm{m}}$ for these substrates of 1-3 $\mu \mathrm{M}$. Moreover, when activated by calcium and $\mathrm{CaM}$, PDE1C represented the major cAMP hydrolytic activity in these cells. Expression of PDE1C was also detected in human SMCs cultured from advanced atherosclerotic lesions of thoracic and carotid arteries.

Currently, five different mRNAs encoding four PDE1C isozymes have been reported in various tissues from mouse, rat, and human species $(34,36,37)$. Two human PDE1C isozymes, designated PDE1C1 (72.2 kD) and PDE1C3 (80.7 $\mathrm{kD})$, are alternatively spliced variants that have been isolated from human hippocampus and human heart cDNA libraries, respectively. Expression of PDE1C has been detected in a limited number of tissues from human sources, including brain, heart, and lung; however, the expression of this isozyme in vascular tissue has not been reported. This is consistent with the idea that PDE1C activity is induced only in proliferating human arterial SMCs. The PDE1C detected in human SMC cultures reported here is about the same size as PDE1C1 found in other human tissues, based on its relative mobility on SDSpolyacrylamide gels. However, more detailed molecular analy-

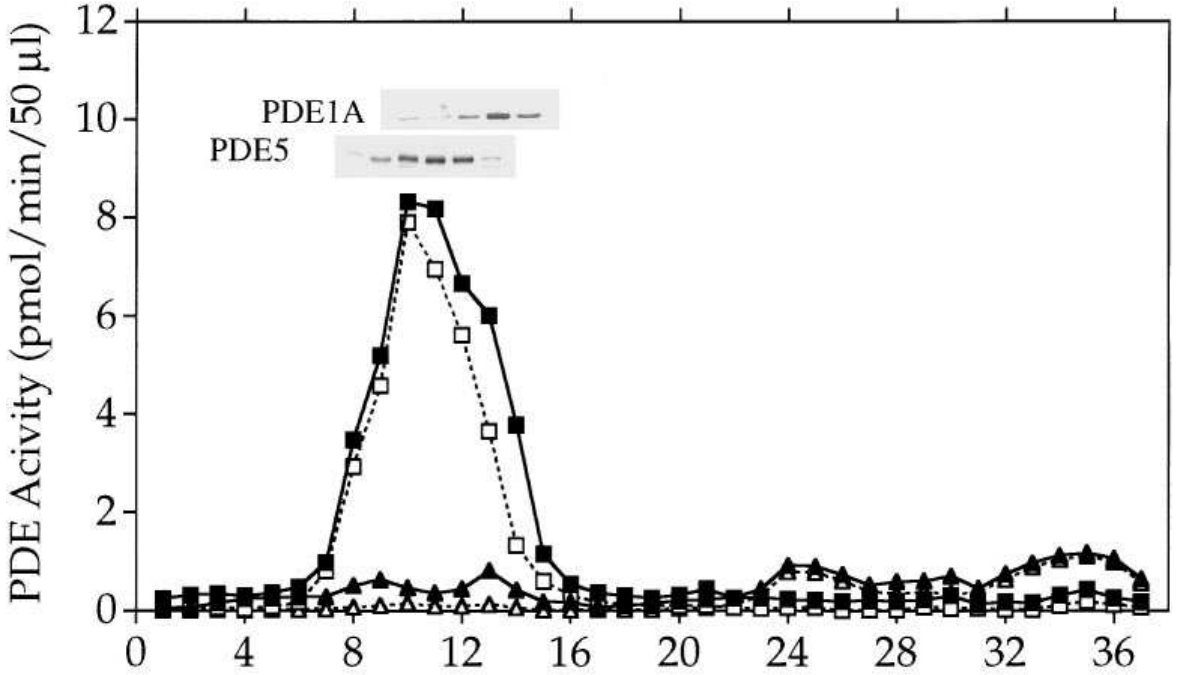

Fraction
Figure 10. Rat SMCs express PDE1A. Anion-exchange chromatography of PDE activity from rat SMCs in primary culture. PDE activity was assayed with either $1 \mu \mathrm{M}$ cAMP (triangles) or $1 \mu \mathrm{M}$ cGMP (squares) in the presence of either $1 \mathrm{mM}$ EGTA (open symbols) or $1 \mathrm{mM} \mathrm{CaCl}_{2}$ and $4 \mu \mathrm{g} / \mathrm{ml}$ $\mathrm{CaM}$ (filled symbols). Immunoblots with detectable bands of PDE1A and PDE5 are shown above their respective chromatographic fractions. 
ses will be needed to identify unequivocally which splice variant of this isoform is expressed.

A PDE1B isoform was detected in the smooth muscle isolated from the medial layer of human aorta but is absent from primary cultures of human SMCs. Currently, only one PDE1B gene has been reported, and no alternative splice variants of this gene have been identified (38). PDE1B is not as widely expressed as PDE1A; however, PDE1B mRNA has been observed in brain, adrenal medulla, and kidney inner medulla, and PDE1B activity has been detected in lectin-activated T-lymphocytes (39). Here, using Western blot analysis, we show that the PDE1B detected in human and monkey aorta, and in cultured monkey SMCs, has a relative mobility $(\sim 60 \mathrm{kD})$ which is lower than recombinant mouse PDE1B1 $(63 \mathrm{kD})$. This slight difference in mobility might reflect differences in the amino acid composition of the PDE1B1 polypeptide between mouse and human species. However, it is also possible that the PDE1B reported here is a new variant of PDE1B due to alternative splicing of the PDE1B gene.

The observation that human SMCs switch from the expression of PDE1B (which hydrolyzes mainly cGMP) in quiescent cells to the expression of PDE1C (which can also hydrolyze cAMP with the same efficiency) in proliferating cells may be explained by the different roles played by these isoforms in regulation of cyclic nucleotide levels. Our preliminary data show that cAMP appears to be a more potent inhibitor of human SMC proliferation than cGMP (data not shown). Therefore, expression of PDE1C rather than PDE1B may be needed in order to keep levels of cAMP low during proliferation.

In contrast to the expression patterns of PDE1C and PDE1B, the PDE1A isoform is present in both human adult aorta and SMCs in primary culture. Currently, two, or possibly three, alternatively spliced variants of this gene have been identified $(30,37)$. The PDE1A1 isoform, which has a relatively higher affinity for $\mathrm{CaM}$ than PDE1A2, is expressed in several bovine tissues, including aorta. PDE1A2 (61 kD) gene expression appears to be restricted to the brain. The isoform identified here is likely to be similar to PDE1A1, since the relative mobility on SDS-polyacrylamide gels is nearly identical to that of recombinant mouse PDE1A1 (59 kD). Interestingly, two peaks of PDE1A were detected in adult monkey and human aorta that may represent enzyme with and without $\mathrm{CaM}$ bound to it. It is not likely that these two peaks represent two different isoforms or proteolytic products, since the immunoreactive bands in both peaks had identical mobility on SDS gels.

The expression pattern of PDE1 isozymes in newborn versus adult human smooth muscle is different. Unlike in adult human aorta, little PDE1 activity was detected in newborn aorta. However, as in adult human SMCs, a large induction of PDE1C was detected in human newborn SMCs in primary culture. The absence of PDE1A in newborn aorta and presence in adult aorta may reflect postnatal developmental changes. Since induction of PDE1C occurs in both adult and newborn human SMCs, it may be a component of a signal transduction pathway that is important for the proliferation of human SMCs at all developmental stages.

The observation that the PDE1 isoforms expressed in aorta and cultured SMCs are dependent on the species was not expected and is quite interesting. For example, PDE1B is the predominant PDE1 isoform expressed in monkey aortic smooth muscle and cultured SMCs. However, PDE1A is the predominant PDE1 isoform expressed in cultured rat SMCs in primary culture. PDE1A was also the only PDE1 isoform detected in bovine SMCs (data not shown). Unlike human arterial smooth muscle, no induction of PDE1C is observed in proliferating SMCs in either of these species. The finding that PDE expression in proliferating human SMCs is different from that in bovine, monkey, and rat SMCs suggests the need to reevaluate pharmacological data about cyclic nucleotide regulation obtained using only nonhuman models and extrapolated to humans. In this case, for example, it is not possible to use rat or monkey models to investigate PDE1C expression after arterial injury. Similarly, data on proliferation of rat smooth muscle using PDE inhibitors may not be relevant to the human artery.

In summary, our experiments reveal that PDE1C is expressed at high levels in proliferative human arterial SMCs, but that expression is absent in smooth muscle in the intact human aorta. It is likely that expression of PDE1C is induced when SMCs are activated to undergo proliferation. Interestingly, induction of another PDE1, most likely PDE1B, has been described in proliferating T-lymphocytes (39). Thus, it is possible that proliferation of some cell types requires induction of a PDE1 to reduce cAMP and/or cGMP levels during proliferation in vivo as well as in primary culture.

The data presented may also have direct relevance to clinical studies involving cyclic nucleotides and smooth muscle proliferation. For example, attempts to treat restenosis after coronary angioplasty using receptor agonists coupled to activation of adenylyl cyclase, such as stable prostacyclin analogues, have not yielded conclusive results (40-42). It is possible that this may be explained in part by the presence of PDEs in the arterial wall that hydrolyze cAMP. Simultaneous stimulation of cAMP synthesis and inhibition of cAMP degradation using selective PDE inhibitors may prove to be more efficacious in the treatment of certain cardiovascular diseases. Therefore, since PDE1C is the predominant cAMP hydrolytic activity in proliferating human SMCs, it would seem to be a likely target for therapeutic intervention in smooth muscle proliferative diseases. Obviously, studies in intact animals will be needed to test this hypothesis.

Note added in proof: Recently, the role of PDEs in the regulation of smooth muscle proliferation has been shown in vivo using a rat model of the balloon catheter-injured artery. Aminophylline (nonspecific inhibitor of PDEs) significantly inhibited neointima formation after balloon injury of rat arterial wall. (Indolfi, C., E.V. Avvedimento, E. Di Lorenzo, G. Esposito, A. Rapacciuolo, P. Giuliano, D. Grieco, L. Cavuto, A.M. Stingone, I. Ciullo, G. Condorelli, and M. Chiariello. 1997. Activation of cAMP-PKA signaling in vivo inhibits smooth muscle cell proliferation induced by vascular injury. Nat. Med. 3:775-779.)

\section{Acknowledgments}

The technical assistance of Li-Chuan Huang, Karen Engel, and Gretchen M. Argast during part of this work is gratefully acknowledged. We thank Dr. Cecilia Giachelli (Department of Pathology, University of Washington) for generous supply of bovine SMCs. The oligonucleotide and peptide synthesis and DNA sequencing were performed by the Molecular Pharmacology Facility, University of Washington. The PDE1C antisera were kindly provided by Dr. Allan Zhao (Department of Pharmacology, University of Washington).

This research was supported in part by a fellowship (S.D. Rybalkin) and grants-in-aid from the Washington Affiliate of the American Heart Association (K.E. Bornfeldt and W.K. Sonnenburg), 
grants from Ono Pharmaceutical Co., Ltd. (Osaka, Japan) and National Institutes of Health grants HL-44948 (J.A. Beavo), DK-42528, and GM-42508 (E.G. Krebs). Monkey aortas were obtained from the Regional Primate Research Center, University of Washington, supported by National Institutes of Health grant RR-00166. Human aortic tissues were obtained from "Biology of the Artery Wall" Tissue and Cell Core (HL-18645), University of Washington. Research on human tissues was approved by the Human Subjects Committee at the University of Washington.

\section{References}

1. Ross, R. 1993. The pathogenesis of atherosclerosis: a perspective for the 1990s. Nature. 362:801-809.

2. Thyberg, J., U. Hedin, M. Sjölund, L. Palmberg, and B.A. Bottger. 1990. Regulation of differentiated properties and proliferation of arterial smooth muscle cells. Arteriosclerosis. 10:966-990.

3. Lindgren, S., A. Rascon, K.E. Andersson, V. Manganiello, and E. Degerman. 1991. Selective inhibition of cGMP-inhibited and cGMP-noninhibited cyclic nucleotide phosphodiesterases and relaxation of rat aorta. Biochem. Pharmacol. 42:545-552.

4. McDaniel, N.L., C.M. Rembold, and R.A. Murphy. 1994. Cyclic nucleotide dependent relaxation in vascular smooth muscle. Can. J. Physiol. Pharmacol. 72:1380-1385.

5. Bornfeldt, K.E. 1996. Intracellular signaling in arterial smooth muscle migration versus proliferation. Trends Cardiovasc. Med. 6:143-151.

6. Cook, S.J., and F. McCormick. 1993. Inhibition by cAMP of Ras-dependent activation of Raf. Science. 262:1069-1072.

7. Graves, L.M., K.E. Bornfeldt, E.W. Raines, B.C. Potts, S.G. Macdonald, R. Ross, and E.G. Krebs. 1993. Protein kinase A antagonizes platelet-derived growth factor-induced signaling by mitogen-activated protein kinase in human arterial smooth muscle cells. Proc. Natl. Acad. Sci. USA. 90:10300-10304.

8. Wu, J., P. Dent, T. Jelinek, A. Wolfman, M.J. Weber, and T.W. Sturgill. 1993. Inhibition of the EGF-activated MAP kinase signaling pathway by adenosine 3', 5'-monophosphate. Science. 262:1065-1069.

9. Graves, L.M., K.E. Bornfeldt, G.M. Argast, E.G. Krebs, X. Kong, T.A. Lin, and J.C. Lawrence, Jr. 1995. cAMP- and rapamycin-sensitive regulation of the association of eukaryotic initiation factor $4 \mathrm{E}$ and the translational regulator PHAS-I in aortic smooth muscle cells. Proc. Natl. Acad. Sci. USA. 92:72227226.

10. Monfar, M., K.P. Lemon, T.C. Grammer, L. Cheatham, J. Chung, C.J. Vlahos, and J. Blenis. 1995. Activation of pp70/85 S6 kinases in interleukin-2responsive lymphoid cells is mediated by phosphatidylinositol 3-kinase and inhibited by cyclic AMP. Mol. Cell. Biol. 15:326-337.

11. Kato, J.Y., M. Matsuoka, K. Polyak, J. Massague, and C.J. Sherr. 1994. Cyclic AMP-induced G1 phase arrest mediated by an inhibitor (p27Kip1) of cyclin-dependent kinase 4 activation. Cell. 79:487-496.

12. Assender, J.W., K.M. Southgate, M.B. Hallett, and A.C. Newby. 1992. Inhibition of proliferation, but not of $\mathrm{Ca}^{2+}$ mobilization, by cyclic AMP and GMP in rabbit aortic smooth-muscle cells. Biochem. J. 268:527-532.

13. Iyengar, R. 1996. Gating by cyclic AMP: expanded role for an old signaling pathway. Science. 271:461-463.

14. Beavo, J.A. 1995. Cyclic nucleotide phosphodiesterases: functional implications of multiple isoforms. Physiol. Rev. 75:725-748.

15. Rybalkin, S.D., and J.A. Beavo. 1996. Multiplicity within cyclic nucleotide phosphodiesterases. Biochem. Soc. Trans. 24:1005-1009.

16. Ahn, H.S., W. Crim, B. Pitts, and E.J. Sybertz. 1992. Calcium-calmodulin-stimulated and cyclic-GMP-specific phosphodiesterases. Tissue distribution, drug sensitivity, and regulation of cyclic GMP levels. Adv. Second Messenger Phosphoprotein Res. 25:271-288.

17. Saeki, T., and I. Saito. 1993. Isolation of cyclic nucleotide phosphodiesterase isozymes from pig aorta. Biochem. Pharmacol. 46:833-839.

18. Lugnier, C., P. Schoeffter, B.A. Le, E. Strouthou, and J.C. Stoclet. 1986. Selective inhibition of cyclic nucleotide phosphodiesterases of human, bovine and rat aorta. Biochem. Pharmacol. 35:1743-1751.

19. Miyahara, M., M. Ito, H. Itoh, T. Shiraishi, N. Isaka, T. Konishi, and T. Nakano. 1995. Isoenzymes of cyclic nucleotide phosphodiesterase in the human aorta: characterization and the effects of E4021. Eur. J. Pharmacol. 284:25-33.

20. Eckly, A.E., and C. Lugnier. 1994. Role of phosphodiesterases III and IV in the modulation of vascular cyclic AMP content by the NO/cyclic GMP pathway. Br. J. Pharmacol. 113:445-450.

21. Vroom, M.B., M. Pfaffendorf, H.B. van Wezel, and P.A. van Zwieten.
1996. Effect of phosphodiesterase inhibitors on human arteries in vitro. Br. J. Anaesth. 76:122-129.

22. Kauffman, R.F., K.W. Schenck, B.G. Utterback, V.G. Crowe, and M.L. Cohen. 1987. In vitro vascular relaxation by new inotropic agents: relationship to phosphodiesterase inhibition and cyclic nucleotides. J. Pharmacol. Exp. Ther. 242:864-872.

23. Pan, X.L., E. Arauz, J.J. Krzanowski, D.F. Fitzpatrick, and J.B. Polson. 1994. Synergistic interactions between selective pharmacological inhibitors of phosphodiesterase isozyme families PDE III and PDE IV to attenuate proliferation of rat vascular smooth muscle cells. Biochem. Pharmacol. 48:827-835.

24. Souness, J.E., G.A. Hassall, and D.P. Parrott. 1992. Inhibition of pig aortic smooth muscle cell DNA synthesis by selective type III and type IV cyclic AMP phosphodiesterase inhibitors. Biochem. Pharmacol. 44:857-866.

25. Ross, R., and B. Kariya. 1980. Morphogenesis of vascular smooth muscle in atherosclerosis and cell culture. In Handbook of Physiology. Section 2: The Cardiovascular System. D.F. Bohr, A.P. Somlyo, H.V. Sparks, and S.R. Geiger, editors. American Physiological Society, Bethesda, MD. 69-91.

26. Beltman, J., D.E. Becker, E. Butt, G.S. Jensen, S.D. Rybalkin, B. Jastorff, and J.A. Beavo. 1995. Characterization of cyclic nucleotide phosphodiesterases with cyclic GMP analogs: topology of the catalytic domains. Mol. Pharmacol. 47:330-339.

27. Hansen, R.S., H. Charbonneau, and J.A. Beavo. 1988. Purification of calmodulin-stimulated cyclic nucleotide phosphodiesterase by monoclonal antibody affinity chromatography. Methods Enzymol. 159:543-557.

28. Bradford, M.M. 1976. A rapid and sensitive method for the quantitation of microgram quantities of protein utilizing the principle of protein-dye binding. Anal. Biochem. 72:248-254.

29. Ausubel, F.M., R. Brent, R.E. Kingston, D.D. Moore, J.G. Seidman, J.A. Smith, and K. Struhl. 1994. Current Protocols in Molecular Biology. John Wiley \& Sons, Inc., New York.

30. Sonnenburg, W.K., D. Seger, and J.A. Beavo. 1993. Molecular cloning of a cDNA encoding the "61 $\mathrm{kDa}$ " calmodulin-stimulated cyclic nucleotide phosphodiesterase. Tissue-specific expression of structurally related isoforms. J. Biol. Chem. 268:645-652.

31. Sonnenburg, W.K., D. Seger, K.S. Kwak, J. Huang, H. Charbonneau, and J.A. Beavo. 1995. Identification of inhibitory and calmodulin-binding domains of the PDE1A1 and PDE1A2 calmodulin-stimulated cyclic nucleotide phosphodiesterases. J. Biol. Chem. 270:30989-31000.

32. McCombie, W.R., C. Heiner, J.M. Kelley, M.G. Fitzgerald, and J.D. Gocayne 1992. Rapid and reliable fluorescent cycle sequencing of doublestranded templates. DNA Seq. 2:289-296.

33. Genetic Computer Group. 1991. Program Manual for the GCG Package. Genetic Computer Group, Madison, WI

34. Yan, C., A.Z. Zhao, J.K. Bentley, and J.A. Beavo. 1996. The calmodulin-dependent phosphodiesterase gene PDE1C encodes several functionally different splice variants in a tissue-specific manner. J. Biol. Chem. 271:2569925706.

35. Harlow, E., and D. Lane. 1988. Antibodies: A Laboratory Manual. Cold Spring Harbor Laboratory, Cold Spring Harbor, NY.

36. Yan, C., A.Z. Zhao, J.K. Bentley, K. Loughney, K. Ferguson, and J.A Beavo. 1995. Molecular cloning and characterization of a calmodulin-dependent phosphodiesterase enriched in olfactory sensory neurons. Proc. Natl. Acad. Sci. USA. 92:9677-9681.

37. Loughney, K., T.J. Martins, E.A. Harris, K. Sadhu, J.B. Hicks, W.K. Sonnenburg, J.A. Beavo, and K. Ferguson. 1996. Isolation and characterization of cDNAs corresponding to two human calcium, calmodulin-regulated, $3^{\prime}, 5^{\prime} \mathrm{cy}-$ clic nucleotide phosphodiesterases. J. Biol. Chem. 271:796-806.

38. Bentley, J.K., A. Kadlecek, C.H. Sherbert, D. Seger, W.K. Sonnenburg, H. Charbonneau, J.P. Novack, and J.A. Beavo. 1992. Molecular cloning of cDNA encoding a " 63 "-kDa calmodulin-stimulated phosphodiesterase from bovine brain. J. Biol. Chem. 267:18676-18682.

39. Hurwitz, R.L., K.M. Hirsch, D.J. Clark, V.N. Holcombe, and M.Y. Hurwitz. 1990. Induction of a calcium/calmodulin-dependent phosphodiesterase during phytohemagglutinin-stimulated lymphocyte mitogenesis. J. Biol. Chem. 265:8901-8907.

40. Knudtson, M.L., V.F. Flintoft, D.L. Roth, J.L. Hansen, and H.J. Duff. 1990. Effect of short-term prostacyclin administration on restenosis after percutaneous transluminal coronary angioplasty. J. Am. Coll. Cardiol. 15:691-697.

41. Gershlick, A.H., D. Spriggins, S.W. Davies, C.Y.D. Syndercombe, J. Timmins, A.D. Timmis, M.T. Rothman, C. Layton, and R. Balcon. 1994. Failure of epoprostenol (prostacyclin, PGI2) to inhibit platelet aggregation and to prevent restenosis after coronary angioplasty: results of a randomised placebo controlled trial. Br. Heart J. 71:7-15.

42. Vane, J.R., and R.M. Botting. 1995. Pharmacodynamic profile of prostacyclin. Am. J. Cardiol. 75:3A-10A. 